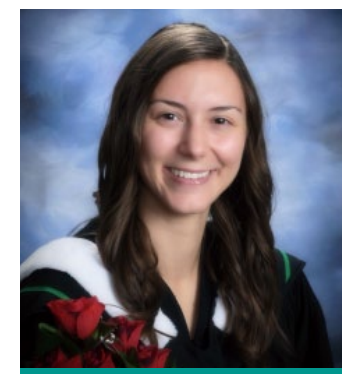

DANA HABICHT

Continuing education is part of a pharmacist's professional

development. We sought to expose the differences in continuing education resources for pharmacist prescribing for ambulatory ailments. This serves as the first step in understanding what form of continuing education will be most helpful to practising pharmacists.

La formation continue joue un rôle dans le perfectionnement professionnel $d u$ pharmacien. Nous avons tenté d'exposer les différences sur le plan des ressources de formation continue destinées aux pharmaciens qui délivrent des ordonnances à des patients ambulatoires. Il s'agit de la première étape pour comprendre quel type de formation continue sera le plus utile aux pharmaciens en exercice.

(C) The Author(s) 2017 DOI:10.1177/1715163517723352

\title{
Incorporating assessment and
} prescribing for ambulatory ailments skills into practice: An environmental scan of continuing education for pharmacist prescribing in Canada

Dana Habicht, BScPharm; Sheila Ng, BScPharm; Drena Dunford, BSc(Hons), BScPharm, CDE; Brenna Shearer, BMR (OT), MSA(HSA), PhD; I fan Kuo, BScPharm, ACPR, MSc, PharmD

\section{ABSTRACT}

Objectives: Pharmacists in Canadian provinces are at different stages of applying prescribing legislation into practice. The purpose of this environmental scan was to examine differences in legislation, remuneration, professional uptake, continuing education requirements and continuing education resources relating to pharmacist prescribing for ambulatory ailments, with a focus on continuing education.

Methods: Data were collected between May and December 2016 using websites and communication with provincial professional regulatory bodies, advocacy bodies, drug coverage programs and other organizations that offer continuing education for pharmacists.

Results: Training requirements to prescribe for ambulatory ailments vary provincially, including no training requirements, online tutorials and a comprehensive application process. Government-funded remuneration for prescribing services is absent in most provinces. Pharmacist uptake of the training required to obtain prescribing authority ranges from $30 \%$ to $100 \%$ of pharmacists. Continuing education programs on the topic of prescribing across the country include online courses, in-person courses, webinars, panel discussions and preparation courses.

Conclusion: Many aspects of pharmacist prescribing for ambulatory ailments, including the style and content of continuing education resources, vary from province to province. Further research on this topic would help to determine the effect of these differences on the success of incorporating pharmacist prescribing into practice. Can Pharm J (Ott) 2017;150:316-325.

\section{Introduction}

The expanded scope of pharmacy practice in Canada has enabled pharmacists to take on new responsibilities, including the ordering of laboratory tests, administration of injectable medications and prescribing of medications for ambulatory ailments. ${ }^{1}$ As of August 2016, pharmacists in the provinces of Alberta, Saskatchewan, Manitoba, Quebec, New Brunswick, Nova Scotia, Prince Edward Island and Newfoundland and Labrador were able to prescribe for ambulatory ailments (often referred to as minor ailments prescribing or prescribing for selflimiting conditions). ${ }^{1}$ 
The legislation, remuneration, professional uptake and continuing education requirements and resources related to pharmacist prescribing vary among different provinces. The purpose of this environmental scan is to examine the differences in these areas with a focus on the continuing education programs that are available in different regions. Ultimately, the data concerning continuing education requirements and resources available across the country will inform those who offer continuing education programs and those who use programs to support legislation. Information collected regarding program length, content and style of existing programs may provide direction for revisions to existing or development of new programs.

\section{Methods}

The authors aimed to collect regional data relating to the following aspects of pharmacist prescribing: continuing education programs (availability, length, accreditation, content, cost and format of delivery), certification requirements, government-funded remuneration, pharmacist uptake of prescribing and which conditions are provincially defined as ambulatory ailments.

Data were collected using a variety of techniques. Information was collected through a review of provincial organizations' websites. Additional information was gathered by e-mail or telephone communication with provincial professional regulatory bodies, advocacy bodies, drug coverage programs and other organizations that offer continuing education for pharmacists. These organizations were contacted by e-mail or telephone. Data were collected by D. Habicht between May and November 2016.

In some provinces, prescribing for smoking cessation is included in legislation for prescribing for ambulatory ailments, and in others it is not. This environmental scan focuses on prescribing for ambulatory ailments and does not go into detail about the training requirements or continuing education available for pharmacist prescribing for smoking cessation.

Canadian provinces and territories in which prescribing for ambulatory ailments is not included in provincial legislation were omitted from this environmental scan because of an absence of data.

\section{Results}

The following is a review of the current training requirements, continuing education programs,

\section{KNOWLEDGE INTO PRACTICE}

- Pharmacists in different provinces are at different stages of applying prescribing legislation into practice.

- Across Canada, pharmacists receive inconsistent support related to the process of prescribing. The certification requirements and continuing education resources for pharmacists vary widely across the country.

- Research evaluating the effects of differences in training and certification requirements on the application of prescribing practice would help to optimize this new role for pharmacists.

remuneration and professional uptake of pharmacist prescribing for ambulatory ailments in the Canadian provinces where prescribing is a part of the expanded scope of pharmacy practice. For the purpose of this environmental scan, continuing education has been defined as any resource developed specifically for the learning purpose of pharmacists. This includes both unaccredited programs and programs accredited by the Canadian Council for Continuing Education in Pharmacy (CCCEP) or provincial programs for continuing education units (CEUs).

Appendix 1 (available in the online version of the article) provides a summary of the continuing education resources available throughout Canada. Table 1 provides an overview of the ambulatory ailments for which pharmacists in different provinces may prescribe. ${ }^{2-9}$ The information is arranged by province.

\section{Alberta}

Additional Prescribing Authorization (APA) is available to pharmacists in Alberta. ${ }^{10}$ APA allows pharmacists to prescribe NAPRA schedule 1 drugs for most conditions (with some exceptions, including narcotics, controlled drugs and benzodiazepines). ${ }^{10}$ The peer-reviewed application process to receive APA includes a selfassessment form, 3 patient cases and 3 case narratives that demonstrate the pharmacist's ability to prescribe. ${ }^{10}$ As of November 8, 2016, approximately $30 \%$ of clinical pharmacists in Alberta have attained APA (Alberta College of Pharmacists, personal communication, November 8,2016 ).

Continuing education on the topic of prescribing has been developed specifically for pharmacists in Alberta. A 2-part course titled Preparing to Apply for Additional Prescribing Authorization 


\section{ORIGINAL RESEARCH}

TABLE 1 Summary of ambulatory conditions for which Canadian pharmacists may prescribe ${ }^{* 1-10}$

\begin{tabular}{|c|c|c|c|c|c|c|c|c|}
\hline & Alberta $^{a}$ & $\begin{array}{l}\text { Saskat- } \\
\text { chewan }\end{array}$ & Manitoba & Quebec & $\begin{array}{c}\text { New } \\
\text { Brunswick }\end{array}$ & $\begin{array}{l}\text { Nova } \\
\text { Scotia }\end{array}$ & $\begin{array}{l}\text { Prince } \\
\text { Edward } \\
\text { Island }\end{array}$ & $\begin{array}{l}\text { Newfound- } \\
\text { land and } \\
\text { Labrador }\end{array}$ \\
\hline$A_{c n e}{ }^{b}$ & $x$ & $x$ & $x$ & $x$ & $x$ & $x$ & $x$ & $x$ \\
\hline Acute mountain sickness prevention & $x$ & & & $x$ & & & & \\
\hline Allergic conjunctivitis & $\mathrm{x}$ & & & $\mathrm{x}$ & & & & \\
\hline Allergic rhinitis & $x$ & $\mathrm{x}$ & $x$ & $x$ & $x$ & $\mathrm{x}$ & $\mathrm{x}$ & $x$ \\
\hline Atopic dermatitis $\left(\right.$ eczema) ${ }^{c}$ & $x$ & $x$ & $x$ & $x$ & $x$ & $x$ & $x$ & $x$ \\
\hline Callouses & $x$ & & & & $x$ & $\mathrm{x}$ & $x$ & $x$ \\
\hline Contact allergic dermatitis $^{d}$ & $x$ & & $x$ & & $x$ & $x$ & $x$ & $x$ \\
\hline Corns & $x$ & & & & $x$ & $x$ & $x$ & $x$ \\
\hline Cough & $x$ & & & & $x$ & $x$ & $x$ & $x$ \\
\hline $\begin{array}{l}\text { Candidal stomatitis (oral thrush, oral } \\
\text { fungal infection) }^{\mathrm{e}}\end{array}$ & $x$ & $\mathrm{x}$ & $\mathrm{x}$ & $\mathrm{x}$ & $x$ & $\mathrm{x}$ & $x$ & $x$ \\
\hline Dandruff & $x$ & & & & $x$ & $x$ & $x$ & $x$ \\
\hline Diaper rash & $x$ & $\mathrm{x}$ & & $\mathrm{x}$ & & & & \\
\hline Diarrhea (noninfectious) & $x$ & & & & $x$ & $x$ & $x$ & $x$ \\
\hline Diarrhea prevention & $\mathrm{x}$ & & & $x$ & & & & \\
\hline Dysmenorrhea (menstrual pain) & $\mathrm{x}$ & $x$ & & $x$ & $x$ & $x$ & $x$ & $x$ \\
\hline Dyspepsia & $x$ & $x$ & & & $x$ & $x$ & $x$ & $x$ \\
\hline Emergency contraception & $x$ & & & $\mathrm{x}$ & $x$ & $x$ & $x$ & $x$ \\
\hline Fever & $x$ & & & & $x$ & & & \\
\hline Fungal infections of the skin ${ }^{f}$ & $x$ & $x$ & & & $x$ & $x$ & $x$ & $x$ \\
\hline Gastroesophageal reflux disease & $x$ & $x$ & & $x$ & $x$ & $x$ & $x$ & $x$ \\
\hline Head lice & $x$ & & & $x$ & & & & \\
\hline Headache $^{g}$ & $x$ & $x$ & & & $x$ & $x$ & $x$ & $x$ \\
\hline Hemorrhoids $^{h}$ & $x$ & $x$ & $x$ & $x$ & $x$ & $x$ & $x$ & $x$ \\
\hline Herpes labialis (cold sores) & $x$ & $x$ & & $x$ & & & & $x$ \\
\hline Herpes simplex & $x$ & & & & $x$ & $\mathrm{x}$ & $x$ & \\
\hline Impetigo & $x$ & & & & $x$ & $x$ & & $x$ \\
\hline Insect bites ${ }^{i}$ & $x$ & $x$ & & & $x$ & $x$ & $x$ & $x$ \\
\hline Irritant contact dermatitis $^{d}$ & $x$ & & $x$ & & & & & $x$ \\
\hline Joint pain (minor or mild) & $x$ & $x$ & & & $x$ & $\mathrm{x}$ & $x$ & $x$ \\
\hline Malaise & $x$ & & & & $x$ & & & \\
\hline Malaria prevention & $x$ & & & $x$ & & & & \\
\hline Migraine & $x$ & $x$ & & & & & & \\
\hline Mouth ulcers (oral ulcers) & $x$ & $x$ & $x$ & $x$ & $x$ & $x$ & $x$ & $x$ \\
\hline Muscle pain (minor or mild) $)^{j}$ & $x$ & $x$ & & & $x$ & $x$ & $x$ & $x$ \\
\hline Nasal congestion & $x$ & & & & $x$ & $x$ & $\mathrm{x}$ & $x$ \\
\hline Nausea & $x$ & & & & $x$ & $\mathrm{x}$ & $x$ & $x$ \\
\hline Nausea/vomiting of pregnancy' & $x$ & & $x$ & $x$ & & & & \\
\hline Pinworms & $x$ & & & & $x$ & $\mathrm{x}$ & $x$ & $x$ \\
\hline Pregnancy (requiring prenatal vitamins) & $x$ & & & $x$ & & & & \\
\hline Seborrhoeic dermatitis $^{m}$ & $x$ & & $x$ & & & & & \\
\hline
\end{tabular}




\begin{tabular}{|c|c|c|c|c|c|c|c|c|}
\hline & Alberta $^{a}$ & $\begin{array}{l}\text { Saskat- } \\
\text { chewan }\end{array}$ & Manitoba & Quebec & $\begin{array}{l}\text { New } \\
\text { Brunswick }\end{array}$ & $\begin{array}{l}\text { Nova } \\
\text { Scotia }\end{array}$ & $\begin{array}{l}\text { Prince } \\
\text { Edward } \\
\text { Island }\end{array}$ & $\begin{array}{l}\text { Newfound- } \\
\text { land and } \\
\text { Labrador }\end{array}$ \\
\hline Sleep disorders (minor or mild) & $x$ & & & & $x$ & $x$ & $x$ & $x$ \\
\hline $\begin{array}{l}\text { Smoking cessation/nicotine } \\
\text { dependence }^{n}\end{array}$ & $x$ & & $x$ & $x$ & $x$ & $x$ & $x$ & $x$ \\
\hline Sore throat $^{\circ}$ & $x$ & & & & $x$ & $X$ & $x$ & $X$ \\
\hline Tinea corporis infection (ringworm) ${ }^{f}$ & $X$ & $X$ & & & $x$ & $x$ & $x$ & $x$ \\
\hline Tinea cruris infection (jock itch) & $x$ & $\mathrm{X}$ & & & $x$ & $x$ & $x$ & $x$ \\
\hline Tinea pedis infection (athlete's foot) ${ }^{f}$ & $X$ & $\mathrm{X}$ & $x$ & & $X$ & $x$ & $x$ & $x$ \\
\hline Urticariai $^{i}$ & $X$ & & $x$ & & $x$ & $x$ & $x$ & $X$ \\
\hline Vaginal candidiasis & $X$ & & & $X$ & $X$ & $X$ & $X$ & $X$ \\
\hline Vasomotor rhinitis & $x$ & & $x$ & & & & & \\
\hline Warts $^{r}$ & $x$ & & & & $X$ & $x$ & $x$ & $x$ \\
\hline Xerophthalmia (dry eyes) & $x$ & & & & & $x$ & $x$ & $x$ \\
\hline
\end{tabular}

Excluding provinces and territories in which prescribing legislation is absent.

${ }^{a}$ The conditions for which pharmacists in Alberta can prescribe is not limited to those represented in this table.

${ }^{b}$ Defined as mild-moderate acne in Saskatchewan, mild/minor acne in Quebec, New Brunswick, Nova Scotia, Prince Edward Island and Newfoundland and Labrador.

'Defined as mild-moderate atopic dermatitis (eczema) in Saskatchewan, Quebec, New Brunswick, Nova Scotia, Prince Edward Island and Newfoundland and Labrador.

${ }^{\mathrm{d}}$ Defined as contact dermatitis by Newfoundland and Labrador.

e Defined as thrush consecutive to the use of corticosteroid inhaler in Quebec.

fDefined as fungal infection of the skin in New Brunswick, Nova Scotia, Prince Edward Island and Newfoundland and Labrador and defined as tinea infection (athlete's foot, jock itch, ringworm) in Saskatchewan.

${ }^{9}$ Defined as mild headache in New Brunswick, Nova Scotia, Prince Edward Island and Newfoundland and Labrador.

hefined as unspecified hemorrhoids without complication in Manitoba.

'Defined as mild urticaria (including bites and stings) in New Brunswick, Nova Scotia, Prince Edward Island and Newfoundland and Labrador. 'Defined as minor joint pain and minor muscle pain in New Brunswick, Nova Scotia, Prince Edward Island and Newfoundland and Labrador and defined as musculoskeletal pain in Saskatchewan.

${ }^{k}$ Defined as mild mouth ulceration in Saskatchewan, mouth ulcers in Quebec, oral ulcers in New Brunswick and recurrent oral aphthae in Manitoba.

'Defined as vomiting of pregnancy (unspecified) in Manitoba and defined as nausea and vomiting of pregnancy in Quebec.

${ }^{m}$ Defined as seborrheic dermatitis (excluding pediatric) in Manitoba.

nIn some provinces, prescribing for smoking cessation and nicotine dependence is included under separate legislation from prescribing for ambulatory conditions.

${ }^{\circ}$ Defined as sore throat (excluding strep throat) in Nova Scotia and upper respiratory conditions (mild-cough, nasal congestion, sore throat) in Newfoundland and Labrador.

${ }^{p}$ Defined as upper respiratory tract conditions (cough, nasal congestion and discharge, sore throat, fever, headache, malaise) in New Brunswick and upper respiratory conditions (mild_cough, nasal congestion, sore throat) in Newfoundland and Labrador.

${ }^{9}$ Defined as urinary tract infection in women in Quebec and defined as uncomplicated urinary tract infection in New Brunswick.

'Defined as warts (excluding facial and genital) in New Brunswick, Nova Scotia, Prince Edward Island and Newfoundland and Labrador.

Course is available through the province's advocacy body, the Alberta Pharmacists Association. ${ }^{11}$ The course includes a 2-hour live session in which pharmacists are instructed on the application requirements and what should be included in a successful APA application, as well as a 3-hour workshop where pharmacists review their applications. The course is accredited by the Alberta 


\section{MISE EN PRATIQUE DES CONNAISSANCES}

- Les pharmaciens des différentes provinces ne sont pas tous au même stade relativement à la mise en pratique des lois relatives à la prescription.

- Dans l'ensemble du Canada, le soutien offert aux pharmaciens est inégal en ce qui touche le processus de prescription. Les exigences de certification et les ressources de formation continue destinées aux pharmaciens varient grandement à l'échelle nationale.

- Une recherche visant à évaluer les effets des différences sur le plan de la formation et des exigences de certification sur les pratiques de prescription aiderait à optimiser ce nouveau rôle des pharmaciens.

Pharmacists Association for 5 CEUs. APA Review Service is another service provided by the Alberta Pharmacists Association that allows a member to submit their APA application documents for review and feedback prior to official application. ${ }^{11}$ Individual large-chain employers and hospitals also have programs to prepare their pharmacists to apply for APA, although no information is available to the public about these programs (Alberta College of Pharmacists, personal communication, May 19, 2016).

Pharmacists in Alberta are compensated for the service of prescribing. Alberta Blue Cross provides pharmacies $\$ 25.00$ for assessment for prescribing at initial access or to manage ongoing therapy. ${ }^{12}$

At this time, students who graduate from accredited Canadian university pharmacy programs do not receive APA upon licensure. A pharmacist must be on the clinical register of pharmacists in Alberta for 1 year prior to consideration for APA (Alberta College of Pharmacists, personal communication, November 8,2016 ).

\section{Saskatchewan}

Pharmacist prescribing for ambulatory ailments (known as "minor ailments" in the province of Saskatchewan) is considered "Level 1 prescribing." ${ }^{13}$ As of August 2013, all licensed pharmacists who practise in a community setting are required to be certified to prescribe for minor ailments. ${ }^{14}$

The courses required for pharmacists to prescribe are available jointly through the University of Saskatchewan (continuing professional development for pharmacists) and The Saskatchewan College of Pharmacists. The courses are Level 1 Basics (information about prescriptive authority for pharmacists) and Prescriptive Authority for Pharmacists-Minor ailments: Part 1 Online Course (or the live version of the course). ${ }^{15}$ Level 1 Basics covers information on legislation, documentation and integrating pharmacy software and is accredited by the province for 5 CEUs. ${ }^{15}$ The Minor Ailments Part 1 Online Course covers the topics of acne, insect bites, cold sores and allergic rhinitis and is accredited by the province for 6 CEUs. Further courses were developed and released as additional conditions were approved for prescribing, but these courses are not required to prescribe for the additional conditions. ${ }^{15}$ These courses include Prescriptive Authority for Pharmacists-Minor Ailments Part 2 Online Course (diaper dermatitis, oral thrush and canker sores) and Prescriptive Authority for Pharmacists Part 3 Online course (atopic dermatitis, hemorrhoids, dyspepsia and GERD, dysmenorrhea, headache including migraine, musculoskeletal strains and pains, superficial bacterial infections, tinea corporis infections, tinea cruris skin infections and tinea pedis infections). ${ }^{15}$ The courses are provincially accredited for 2.5 CEUs and 5 CEUs, respectively. Guidelines and algorithms to assist pharmacists in assessing and prescribing for each condition are available online through the MedSask (the University of Saskatchewan) website. ${ }^{2}$

Pharmacy services in Saskatchewan are remunerated through the Saskatchewan drug plan. The plan provides pharmacies an $\$ 18.00$ assessment fee for the prescribing of minor ailments. ${ }^{16}$

Pharmacy students graduating from the University of Saskatchewan College of Pharmacy and Nutrition receive the necessary training for Level 1 prescribing authority in the curriculum of the pharmacy program and are authorized to prescribe upon licensure (Saskatchewan College of Pharmacy Professionals, personal communication, November 13, 2016).

\section{Manitoba}

In Manitoba, pharmacists must complete the Self-limiting Conditions Independent Study Program, which is available online through the Advancing Practice website, prior to engaging in prescribing activities. The program is a 15 -hour online module that includes information on safe prescribing in Manitoba and clinical information on ambulatory ailments and is provincially accredited for 15 CEUs. ${ }^{17}$ As of July 21, 2016, $37 \%$ of pharmacists (548 of 1501) in Manitoba were certified to prescribe for ambulatory 
ailments (Pharmacists Manitoba, personal communication, August 9, 2016).

Continuing education on the topic of prescribing specific to pharmacists in Manitoba has been offered jointly through the province's advocacy body, Pharmacists Manitoba and the University of Manitoba. A provincially accredited, 6.5-hour in-person workshop titled Assessment and Prescribing for Ambulatory Ailments has been offered to Manitoban pharmacists a total of 3 times over 2014 and 2015. The workshop included information on legal requirements for pharmacists' prescribing and clinical reviews of select conditions that pharmacists may prescribe for in the province (College of Pharmacy, University of Manitoba, personal communication, May 26, 2016).

There is presently no remuneration for the service of pharmacist prescribing in Manitoba.

Starting in 2017, students who graduate from the accredited pharmacy program at the University of Manitoba will be certified to prescribe for ambulatory ailments upon licensure with the College of Pharmacists of Manitoba (College of Pharmacists of Manitoba, personal communication, November 14, 2016).

\section{Quebec}

Pharmacists in the province of Quebec can prescribe medications under 2 categories: prescribing when no diagnosis is required and prescribing for ambulatory ailments. ${ }^{18}$ All licensed pharmacists in the province may prescribe medications when a diagnosis is not required, but further training is required for a pharmacist to prescribe for ambulatory ailments. ${ }^{18}$

The mandatory training required to prescribe for ambulatory ailments in Quebec is in the form of a self-directed online module. ${ }^{19}$ The course combines training for prescribing medications, laboratory analysis, adjusting and extending prescriptions and substituting a prescribed drug. The course covers regulatory, procedural and monitoring requirements of prescribing. The training is provincially accredited for 5 CEUs and is approximately 4.5 hours in duration. ${ }^{20}$

No continuing education resources related to pharmacist prescribing other than the certification course were identified for pharmacists in the province of Quebec.

Pharmacists in Quebec receive compensation for the service of prescribing at a rate of $\$ 16.00$. This fee is supplied by both private insurers and the public drug coverage plan, Régie de lassurance maladie du Québec (RAMQ) (RAMQ, personal communication, May 24, 2016). As of August 16, 2016, 4801 pharmacists (approximately 55\% of licensed pharmacists) have been certified to prescribe in the province of Quebec (Ordre des pharmaciens du Quebec, personal communication, August 16, 2016). ${ }^{21}$

Pharmacy students graduating from accredited pharmacy university programs are required to take the same required training course as licensed pharmacists prior to engaging in prescribing for ambulatory ailments (Ordre des pharmaciens du Quebec, personal communication November 25, 2016).

\section{New Brunswick}

Pharmacists in New Brunswick must declare to have participated in a Minor Ailments Orientation (attending in person, reading the written document or watching recorded video presentation) offered through the New Brunswick College of Pharmacists prior to engaging in prescribing activities. ${ }^{22}$ The orientation includes legislation change descriptions and the process and documentation requirements for prescribing. The recorded presentation is 1 hour 46 minutes long. ${ }^{23}$ As of May 24, 2016, 55\% of pharmacists ( 475 out of 858 ) in New Brunswick have signed off as being prepared to prescribe for minor/ambulatory ailments (New Brunswick College of Pharmacists, personal communication, May 24, 2016).

As there is no university pharmacy program in New Brunswick, few continuing education resources have been developed specifically for the province's pharmacists. However, the New Brunswick Pharmacists Association advertises the Canadian Pharmacists Association continuing education course on the topic of minor ailments prescribing and collaborates with Dalhousie's continuing education division in offering their courses. ${ }^{24}$ For the 2016 New Brunswick Pharmacists Association annual conference, a panel discussion on prescribing for minor ailments took place (New Brunswick Pharmacists' Association, personal communication, May 25, 2016). Continuing education materials from other provinces are also listed on the New Brunswick College of Pharmacists website.

There is currently no remuneration for the service of prescribing by pharmacists in New Brunswick. 
Nova Scotia

All licensed pharmacists in Nova Scotia may prescribe for ambulatory ailments without additional training other than cardiopulmonary resuscitation (CPR) and first-aid training. ${ }^{7}$ Each pharmacist must judge whether or not he or she is competent to prescribe for a condition and seek additional training if necessary. ${ }^{7}$

Although no training is required to prescribe, the University of Dalhousie has developed online continuing education sessions for pharmacists in Nova Scotia. The Prescribing for Minor AilmentsMini Modules programs include Documentation for Pharmacists, General Patient Assessment, Eczema, Dermatitis and Urticaria, GERD, Threadworms and Pinworms, Muskuloskeletal Disorders and Acne, Warts and Dandruff. The programs are each accredited provincially for 1 CEU. ${ }^{6}$

The Minor Ailments Assessment One-Year Demonstration Project was scheduled to run from May 4, 2015, to May 3, 2016, and was extended to run until November 4, 2016 (Nova Scotia Pharmacare Program, personal phone call, June 21, 2016). ${ }^{25}$ The project involves the Nova Scotia Pharmacare program providing a $\$ 20.00$ service fee to pharmacists when they complete assessment to prescribe for cold sores, allergic rhinitis or skin conditions. ${ }^{25}$

\section{Prince Edward Island}

Pharmacists in Prince Edward Island (PEI) are required to complete 1 of 2 approved programs in addition to holding CPR and first-aid certification prior to engaging in prescribing activities. The 2 approved programs are Dalhousie Continuing Pharmacy Education Division's Prescribing for Minor Ailments in the Maritimes (accredited 18 CEUs by Dalhousie Continuing Pharmacy Education) and PEI College of Pharmacists' Prescribing for Minor Ailments in PEI (accredited 2.5 CEUs by the PEI College of Pharmacists). ${ }^{26}$ The former includes an online component and a 1-day in-person workshop, while the latter is a recorded webinar (PEI College of Pharmacists, personal communication, August 26, 2016). ${ }^{26}$ As of May 31, 2016, 123 pharmacists, approximately $70 \%$ of pharmacists in PEI, hold an extended practice certificate in minor ailment prescribing (PEI College of Pharmacists, personal communication, May 31, 2016).

In addition to the certification course, a webinar available through the PEI College of Pharmacists website titled Understanding New Legislation in PEI has been developed specific to pharmacists in PEI. ${ }^{27}$ This webinar is accredited for $1.5 \mathrm{CEUs}$ by the PEI College of Pharmacists. Like other provinces in the Maritimes, the PEI Pharmacists Association encourages use of continuing education materials offered through Dalhousie University (Prince Edward Island Pharmacists Association, personal communication, May 18, 2016).

Currently, no remuneration is provided to pharmacists for providing prescribing services.

Pharmacy students graduating from accredited Canadian university pharmacy programs are required to take 1 of the approved programs to attain an Extended Practice Certificate in Minor Ailment Prescribing. As of November 2016, this requirement is under review by the PEI College of Pharmacists (PEI College of Pharmacists, personal communication, November 14, 2016).

\section{Newfoundland and Labrador}

Pharmacists in Newfoundland and Labrador (NL) are required to take the course, An Orientation to Prescribing by Pharmacists in Newfoundland and Labrador (1.5 CEUs), offered online through the Advancing Practice website in order to be certified to prescribe for ambulatory ailments. ${ }^{9,28}$ As of November 15, 2016, 72\% of all registered pharmacists (541 of 751) in NL and $87 \%$ (429 of 492 ) of community pharmacists are authorized to prescribe (Newfoundland and Labrador Pharmacy Board, personal communication, November 15, 2016).

The Prescribing Standard from the Newfoundland and Labrador Pharmacy Board states that "professional development should be undertaken, as necessary, to maintain knowledge and skills," but there are no official requirements for continuing education related to prescribing. ${ }^{9}$ The Pharmacists Association of Newfoundland and Labrador offers content at their annual conferences related to the topic of prescribing for minor ailments, for example, a presentation on assessing and prescribing for minor muscle or joint pain and a presentation related to skin-related minor ailments (the Pharmacists Association of Newfoundland and Labrador, personal communication, May 19, 2016). The Newfoundland and Labrador Pharmacy Board and Memorial University jointly offered a continuing education presentation titled An Approach to Patient Assessment for Minor Ailments in June 2016 (School of Pharmacy, Memorial University of Newfoundland, personal communication, August 12, 2016). 
This presentation was provincially accredited for 1 CEU (Pharmacists Association of NL, personal communication, August 23, 2016).

There is no remuneration available to pharmacists in NL for the service of prescribing.

The Newfoundland and Labrador Pharmacy Board requires new graduates from accredited Canadian University pharmacy programs to complete the required course prior to engaging in prescribing activities (Newfoundland and Labrador Pharmacy Board, personal communication, November 9, 2016).

\section{Additional continuing education resources}

The Canadian Pharmacists Association offers a continuing professional development program titled Assessing and Prescribing for Minor Ailments (35.25 CEUs) ${ }^{29}$ It is a self-directed online program that uses online modules to educate about clinical topics on 32 conditions, including assessment, red flags for referral, treatment, counselling, monitoring and follow-up for the conditions. ${ }^{29}$ A program titled Minor Ailments Therapeutic Modules is available to Shoppers Drug Mart employees. The program is CCCEP accredited for 4 CEUs and is a series of online modules that include information about ambulatory/minor ailments assessment, treatment and follow-up. ${ }^{30}$ These programs are available to pharmacists across the country and are not specific to prescribing in a particular province. After completing these courses, pharmacists remain limited to prescribe only for the conditions included in their province of licensure's scope of prescribing.

\section{Discussion}

This environmental scan demonstrates that Canadian provinces are at different stages of incorporating prescribing into pharmacy practice. An awareness of the differences between provinces should be sought when pharmacists, governments, regulatory bodies and advocacy bodies are approaching and making important decisions regarding pharmacist prescribing.

A scoping review of research on the prescribing practice of Canadian pharmacists published in 2015 examined available literature on the topic of pharmacist prescribing in Canada. No articles identified focused on the variety of continuing education resources available to pharmacists. ${ }^{31}$ This environmental scan is the first to address this topic. The continuing education resources available to pharmacists vary widely between provinces and include programs aiding pharmacists to achieve prescribing authority, online courses, live sessions and panel discussions. The training requirements needed to prescribe also vary widely between provinces, from no training requirements in Nova Scotia to a comprehensive application demonstrating a pharmacist's ability to prescribe in Alberta.

Although the environmental scan successfully demonstrates inconsistencies in the application of pharmacist prescribing across Canada, a number of limitations should be addressed. First, the information represented in this environmental scan will become outdated as the resources, remuneration and uptake of prescribing by pharmacists will inevitably change in coming years. Second, a portion of the data presented was attained through personal communication with individuals who represent various provincial organizations. While this was considered the best means to attain certain information, reproducing the research process may be a challenge. The inconsistency in provincial regulations, range of prescribing authority and access to documented processes and policies limits the ease of accurately drawing comparisons between provinces. It should be noted that there is an absence of high-quality outcome data pertaining to the value of pharmacist prescribing models and that this environmental scan does not provide any additional outcome data. ${ }^{31}$ Such limitations are inherent to this research.

Pharmacist prescribing has the potential to provide patients with improved access to quality health care. Further research is required to investigate the effect of different funding frameworks, continuing education resources and legislation requirements for education on the uptake, application and success of pharmacist prescribing. This environmental scan represents the first portion of research being conducted in Manitoba investigating pharmacist prescribing practices. Further research on this topic is being conducted to investigate pharmacists' perspective through the use of a survey, thereby complementing and concluding this environmental scan.

\section{Conclusion}

Pharmacists are at various stages of incorporating prescribing for ambulatory ailments into practice across Canada. Along with many other aspects of pharmacist prescribing, the continuing education resources and requirements 
available to pharmacists are highly variable in different provinces. Research concerning the success of different styles of continuing education programs would be valuable to ensure that pharmacists have access to optimal tools while progressing as prescribers. Research evaluating the effects of the numerous differences in prescribing practice application across Canadian provinces would aid in optimizing this new role for pharmacists.

From the College of Pharmacy (Habicht, Ng, Dunford, Shearer, Kuo), University of Manitoba; and Pharmacists Manitoba (Shearer), Winnipeg, Manitoba. S. Ng and D. Dunford are PharmD candidates at the University of Colorado. Contact Sheila.Ng@umanitoba.ca.

Acknowledgments: The financial support from the College of Pharmacy to D. Habicht and from District Five NABP/AACP is gratefully acknowledged.

Author Contributions: D. Habicht contributed to the study conception, methodology, investigation, data curation and writing and manuscript preparation. S. Ng was involved in study conception, methodology, supervision, funding acquisition and critical review. D. Dunford contributed to study conception, methodology, supervision, funding acquisition and critical review. B. Shearer took part in study conception and critical review. I. Kuo took part in critical review.

Declaration of Conflicting Interests: D. Dunford contributed to the CPhA Continuing Education: Assessing and Prescribing for Minor Ailments: Urticaria Module. D. Dunford, S. Ng and B. Shearer were involved in providing the continuing education program Assessment and Prescribing for Ambulatory Ailments Workshop offered in Manitoba.

Funding: The authors gratefully acknowledge a $\$ 1500$ study grant from District Five NABP/AACP and $\$ 8000$ University of Manitoba Undergraduate Summer Research Scholarship in Pharmacy to D. Habicht.

\section{References}

1. Canadian Pharmacists Association. Pharmacists' expanded scope of practice. Available: www.pharmacists.ca/pharmacyin-canada/scope-of-practice-canada/ (accessed Jun. 21, 2016).

2. The University of Saskatchewan. MedSask guidelines for minor ailment prescribing. Available: http://medsask.usask.ca/ professional/guidelines/index.php (accessed May 26, 2016).

3. College of Pharmacists of Manitoba. Available drugs for prescribing under schedule 3 of the Manitoba Pharmaceutical Regulations. Available: http://mpha.in1touch.org/uploaded/ web/Legislation/Pharmacist\%20prescribing\%20-Drugs\%20 available\%20under\%20Schedule\%203.pdf (accessed May 20, 2016).

4. Order des Pharmaciens du Quebec. Prescrire un medicament lorsquaucun diagnostic n'est requis. Available: www.opq.org/ fr-CA/grand-public/nouvelles-activites-des-pharmaciens/ comprendre-les-nouvelles-activites/prescrire-des-medicam ents-aucun-diagnostic-requis/ (accessed May 17, 2016).

5. Order des Pharmaciens du Quebec. Prescrire des medicaments pour certaines conditions mineures. Available: www .opq.org/fr-CA/grand-public/nouvelles-activites-des-phar maciens/comprendre-les-nouvelles-activites/prescriredes-medicaments-pour-certaines-conditions-mineures/ (accessed May 17, 2016).

6. New Brunswick College of Pharmacists. Pharmacists' expanded scope: minor ailments. Available: https:// nbcp.in1 touch.org/document/1698/Pharmacists\%20
Expanded\%20Scope_Minor\%20Ailments\%20docum ent\%20update\%20May2015\%20EN.pdf (accessed May 19, 2016).

7. Nova Scotia College of Pharmacists. Standards of practice: prescribing of drugs by pharmacists. Available: www .nspharmacists.ca/wp-content/uploads/2016/05/NSCP_ SOP_Prescribing_of_Drugs_by_Pharmacists.pdf (accessed May 20, 2016).

8. Prince Edward Island College of Pharmacists. Practice directive; prescribing of drugs by pharmacists. Available: http:// pei.in1touch.org/uploaded/web/PEI\%20Proposed\%20Stand ards\%20for\%20Prescribing\%20final\%20draft.pdf (accessed May 25, 2016).

9. Newfoundland and Labrador Pharmacy Board. Standards of practice; prescribing by pharmacists. Available: www.nlpb .ca/media/SOPP-Prescribing-by-Pharmacists-Aug2015revFeb2016.pdf (accessed May 26, 2016).

10. Alberta College of Pharmacists. Guide to receive additional prescribing authorization. Available: https://pharmac ists.ab.ca/ sites/default/files/APAGuide.pdf (accessed May 25, 2016).

11. Alberta Pharmacists Association. Additional prescribing authorization. Available: https://www.rxa.ca/professionaldevelopment/apa.aspx (accessed May 25 and November 8th, 2016).

12. Alberta Blue Cross. Pharmacy benefact number 446. Available: https://www.ab.bluecross.ca/pdfs/82320.446.pdf (accessed May 24, 2016). 
13. Saskatchewan College of Pharmacy Professionals. Regulatory bylaws of the Saskatchewan College of Pharmacy Professionals part K prescribing of drugs. Available: http://scp .in1 touch.org/uploaded/web/refmanual/Bylaws-Regulatory_CURRENT.pdf (accessed May 23, 2016).

14. Saskatchewan College of Pharmacy. Prescriptive authority training mandatory for this year's practicing membership renewal. SCOPE e-newsletter. 2014;6(1):1-1. Available from: http://saskpharm.ca/document/1504/SCOPe_V6_ Issue\%201_Mar2014_FINAL3.pdf (accessed May 15, 2016). 15. The University of Saskatchewan College of Pharmacy and Nutrition. Continuing professional development for pharmacy professionals. Available: www.usask.ca/cpdpp/continuingeducation-/Online\%20Courses.php\#AbouttheCourses (accessed Nov. 8, 2016).

16. Saskatchewan Drug Plan. Patient assessment fee submissions. Bulletin 566. April 29, 2014.

17. Advancing Practice. Self-limiting conditions independent study program. Available: www.advancingpractice.com/p78-self-limiting-conditions-independent-study-program. aspx (accessed May 20 and Nov. 8, 2016).

18. Ordre des Pharmaciens du Quebec. Application de la Loi 41 formation. Available: www.opq.org/fr-CA/pharmaciens/ application-de-la-loi-41/formation-loi-41/ (accessed May 17, 2016).

19. Order des Pharmaciens du Quebec. Loi 41: une formation obligatoire avant d'exercer certaines des nouvelles activites. Available: www.opq.org/fr-CA/pharmaciens/applicationde-la-loi-41/formation-loi-41/formation-reglementaire/ (accessed May 17 and Nov. 8, 2016).

20. Ordre des Pharmaciens du Quebec. Loi 41 nouvelles activites. Available: www.opq.org/cms/Media/1562_38_fr-CA_0_ Depliant_formation_reglementaire_automne2013.pdf (accessed May 17, 2016).

21. National Association of Pharmacy Regulatory Authorities. Provincial/territorial statistics-pharmacists. Available: http://napra.ca/pages/Practice_Resources/National_Statist ics.aspx?id=2103 (accessed Dec. 1, 2016).
22. New Brunswick College of Pharmacists. Professional practice requirements. Available: www.nbpharmacists.ca/site/ practice-rqmts (accessed May 18, 2016).

23. New Brunswick College of Pharmacists. Minor ailments orientation 2014 (English) [Video]. Available: https://www .youtube.com/watch?v=w1FqnFw1Zdg\&feature=youtu.be . Published June 30, 2014. Accessed May 18, 2016.

24. Dalhousie University. Continuing pharmacy education online programs and webinars. Available: www.dal.ca/ facu lty/healthprofessions/cpe/programs/online-programsandwebinars.html (accessed May 20 and Nov. 8, 2016).

25. Nova Scotia Pharmacare. Nova scotia formulary updates minor ailments assessment one-year demonstration project. Pharmacare News e-newsletter. 2015;15(3). Novascotia.ca. http:// novascotia.ca/dhw/pharmacare/pharmacists_bulletins/Phar macists_Bulletin_April_15-03.pdf(accessed May 25, 2016).

26. Prince Edward Island College of Pharmacists. Extended practice certifications. Available: http://pepharmacists.ca/ site/epc (accessed May 25, 2016).

27. Prince Edward Island College of Pharmacists. Continuing education. Available: http://pepharmacists.ca/site/ce (accessed May 25, 2016).

28. Advancing Practice. An orientation to prescribing by pharmacists in Newfoundland and Labrador. Available: www .advancingpractice.com/p-90-an-orientation-to-prescrib ing-by-pharmacists-in-newfoundland-and-labrador.aspx (accessed May 26, 2016).

29. Canadian Pharmacists Association. Minor ailments $C P D$. Available: www.pharmacists.ca/education-practiceresources/professional-development/minor-aliments-cpd/ (accessed Jun. 20, 2016).

30. Canadian Council on Continuing Education in Pharmacy. Program information. Available: www.cccep.ca/ show_prov_program.php?provider_prog_id $=2133 \&$ ac $=0$ (Accessed Aug. 23, 2016).

31. Chowdhury FF, Guirguis LM. A scoping review of research on the prescribing practice of Canadian Pharmacists. Can Pharm J (Ott) 2015;148(6):325-48. 